\title{
MATILDE HUICI INSPIRADORA DE LA EDUCACIÓN DE PÁRVULOS UNIVERSITARIA DURANTE EL ESTADO DOCENTE CHILE 1944 A 1962
}

\author{
MATILDE HUICI, INSPIRER OF UNIVERSITY EARLY CHILDHOOD \\ EDUCATION DURING THE CHILEAN TEACHING STATE 1944-1962
}

Benjamín Silva Torrealba ${ }^{1}$ Doctor (c) en Historia Universidad de Chile benjamin@cecamericana.cl

Carolina Figueroa Cerna ${ }^{2}$ Doctora (c) en Historia Universidad Nacional de Centro de la Provincia de Buenos Aires carocernaf@gmail.com

\begin{abstract}
Resumen: El presente texto es un estudio preliminar sobre la acción pedagógica y práctica docente de la profesora Matilde Huici, como inspiradora central de la carrera de Educación de Párvulos en la Universidad de Chile, durante los años 1944 a 1962. Para elaborar este trabajo, se hicieron y analizaron 10 entrevistas semiestructuras de estudiantes y docentes de dichos años, elaborando por esa vía, las líneas gruesas de la acción académica de la profesora Huici. Por medio del mencionado camino, planteamos como hipótesis global que la acción pedagógica de esta maestra española en la Casa de Bello, estuvo caracterizada por: un marcado componente ético antropológico, el cual se basó en una clara aplicación del método científico y en un potente marco teórico, con lo cual planteó un claro, innovador y público reconocimiento a las potencialidades educativas de la formación inicial infantil.
\end{abstract}

Palabras claves: Matilde Huici, estado docente, historia educación de párvulos.

Abstract: This text is a preliminary study on the pedagogical action and teaching practice of Professor Matilde Huici, as a central inspirer of the Early Childhood Education career at the Universidad de Chile, during the years 1944 to 1962. To elaborate this work, 10 semistructured interviews of students and teachers of those years were made and analyzed, elaborating in this way, the main lines of the academic action of Professor Huici. Using the mentioned way, we propose as a global hypothesis that the pedagogical action of this Spanish teacher in the Casa de Bello was characterized by: a marked anthropological ethical component, which was based on a clear application of the scientific method and on a powerful theoretical framework, with which she proposed a clear, innovative and public recognition to the educational potentialities of the initial childhood education.

${ }^{1}$ Coordinador Centro de Educación y Cultura Americana CECA

${ }^{2}$ Investigadora asociada Centro de Educación y Cultura Americana CECA 
Key words: Matilde Huici, teaching state, history of early childhood education.

\section{INTRODUCCIÓN}

La educación de párvulos o ciclo inicial, como uno de los sectores del sistema educativo chileno junto con la educación diferencial, ha sido un ámbito de trabajo con un menor grado de estudios históricos sobre su desarrollo. Lo anterior se tensiona con la fuerte relevancia que la educación inicial ha adquirido en los últimos años en Chile con frases como: "los niños van primero" o con la propuesta de "sala cuna universal". Muchas de las ideas, soportes ideológicos y propuestas que hoy se levantan como nuevas o innovadoras, han sido sostenidas y defendidas con fuerza, coherencia y mucha evidencia empírica por protagonistas y educadoras de párvulos desde los comienzos de su historia, a mediados del siglo XIX; sin embargo, adquirió una nueva relevancia en 1944, con la creación de la carrera universitaria de este ámbito de la enseñanza. Debido a ello, hemos decidido presentar en este artículo una versión resumida y preliminar de un arco temporal del desarrollo de la educación inicial en Chile, de forma más específica entre los años 1944 y 1964, para evidenciar las características de dicho sector de la enseñanza en su ámbito universitario, pero con un ojo puesto en demostrar que muchas de estas ideas y planteamientos de dichos lustros forman parte del debate actual sobre políticas públicas.

Hemos desarrollado la historia de la educación de párvulos en Chile entre los 1810 a 1973 en cuatro períodos. El primero de ellos ha sido trabajado por la profesora María Victoria Peralta en su muy extensa y bien desarrollada bibliografía. Dicha autora indica que este ámbito de la enseñanza se originó en la segunda mitad del siglo XIX, cuando se crearon los primeros jardines infantiles con un bajo nivel de cobertura e impacto. De esta forma, dichos establecimientos siguieron su vida con grandes falencias y dificultades, -con cierres y nuevas aperturas- hasta principios del siglo XX (Peralta, 2006, 2009, 2011, 2013 y 2015).

Un segundo momento la profesora Peralta (2006, 2007, 2008a , 2008b, 2008c, 2009, 2011, 2012ª , 2012b, 2013 y 2015) en compañía de otros trabajos (Alarcón, 1986; Caiceo, 2011; Abett de La Torre, 2011 2013; Grabivker, 2012; Cisternas, 2014; Grabivker y Cisternas, 2016) han postulado que entre 1900 y 1920 hubo un florecimiento de la educación de párvulos, debido al arribo de la profesora Leopoldina Maluschka. Esta educadora austriaca llegó a Chile en los años del llamado embrujo alemán, entre 1880 y 1920 (Labarca, 1939; Serrano, Ponce de León y Rengifo, 2012; Silva, 2015, 2016aㅗ $2017^{a}$ y $2018^{a}$ ). Desde su llegada, en 1889, Maluschka se dedicó a la difusión y relevancia de la educación de párvulos, centrando su aporte desde comienzos del siglo XX en la formación de maestras normales con especialidad de Kindergarten, las llamadas kindergartinas, basadas en el modelo de Fröebel. Además, escribió en un conjunto global de revistas educativas, difundiendo sus ideas y logrando un aumento en la creación de jardines infantiles, hasta la crisis económica chilena, consecuencia de la I Guerra Mundial (1914-1918) donde comenzó el fin del modelo, debido al llamado rentismo salitrero (Silva, 2016b).

Un tercer período de la historia de la educación de párvulos se centró en los años veinte del siglo XX hasta 1944, con el mayor influjo de las ideas de la Escuela Nueva o Activa 
(Palacios, 2010), tanto en el sistema escolar como a nivel global nacional (Caiceo, 1995a 2002, 2005, 2008, 2016 y 2016b), como sobre el desarrollo del sistema de educación inicial (Peralta, 2006, 2008á, 2008b, 2008c, 2010 y 2015; Alarcón, 1986; Caiceo, 2011). Dentro de estos años, se consolidó el aporte con más fuerza de las ideas de María Montessori en el sector inicial de la enseñanza (Peralta, 2007 y 2012 ${ }^{a}$ ) con el arribo de los postulados de Ovide Decroly (Peralta, 2008a ); durante aquel tiempo una de las defensoras y promotoras de este ámbito de la educación fue Gabriela Mistral (Peralta 2012b; Núñez y Pérez, 2015). Finalmente, en los años de la llamada Reforma de los Profesores de 1928 (Núñez, 1979, 1982b, 1986, 1989, 1995b, 1997a , 2003, 2005, 2007, 2012 y 2017; Reyes 2003, 2005 у 2013; Hernández y Zamorano, 2016) se dio un nuevo reflorecimiento de la promoción de la educación de párvulos, como ha estudiado recientemente la profesora Peralta (2018). Con posterioridad a esta transformación, tanto los debates sobre la educación inicial como del conjunto del sistema educativo, tuvieron una disminución, debido a los conflictos políticos gestados en el segundo gobierno de Arturo Alessandri Palma (1932-1938) y el rápido término por fallecimiento del presidente Pedro Aguirre Cerda (1938-1941), quien lideró el llamado Frente Popular (Vial, 2001 y 2010; Zemelman y Jara, 2006).

Un cuarto momento se desarrolló entre los años 1944 y 1973. El primer hito del mismo fue la creación de la carrera de educación de párvulos en la Universidad de Chile, idea sostenida por la educadora Amanda Labarca y patrocinada por el rector de dicha casa de estudios, Juvenal Hernández (Alarcón, 1986; Caiceo, 2011; Abett de la Torre, 2013; Peralta, $2012 b$ ), quienes con fuerza y convicción enfrentaron los prejuicios y oposiciones que la fundación de dicha carrera despertó tanto en el seno de la Universidad como en la sociedad chilena (Araya, Silva e Iturriaga, 2018). Durante estos años, como se ha estudiado en recientes trabajos, destacaron las educadoras como protagonistas, las cuales se aglutinaron en torno a la lucha social, ciudadana y política para poder tener una Ley e institucionalidad especiales que promovieran un aumento sustantivo de la educación inicial; debate que finalmente dio vida, en 1970, a pocos meses del término de la administración de Eduardo Frei Montalva (1965-1970), al cuerpo legislativo que creó la Junta de Jardines Escolares (JUNJI), entidad que comenzó a funcionar durante los tres años que duró la Unidad Popular (Rojas, 2010; Abett de la Torre, 2013; Mendoza y Ferrer, 2015 y 2015).

En el presente estudio nos centraremos en este último período de la historia de la educación inicial, durante la vigencia del Estado Docente preocupado por sus aulas (Silva, 2018b). De forma más específica abarcaremos los años que van entre 1944 y 1962, que son los años del ejercicio como directora de la Escuela de Educación de Párvulos en la Universidad de Chile de la abogada, psicopedagoga y gran educadora española-vasca Matilde Huici, quien murió dos años después, en 1964. De esta forma pretendemos analizar las ideas basales de la acción educativa y el pensamiento pedagógico de la profesora Matilde, por medio del registro de entrevistas a un grupo de sus estudiantes. Para lograr dicha meta, durante el segundo semestre de 2017 y el primer semestre de 2018, entrevistamos, por medio de un cuestionario semi estructurado, a diez profesionales de la educación inicial de estos años de estudio, siendo ocho de ellas (Ester Pretch, Alicia Navarro, Dina Alarcón, Ema Romero, Luisa Revecco María Luz Roa, María Lechuga e Ivonne Fontaine) egresadas de la primera carrera universitaria de educación de párvulos de la Casa de Bello. Adriana Otero, psicóloga y profesora de la carrera durante los lustros estudiados, y Magaly Núñez, profesora 
normalista con mención en Kindergarten, quienes jugaron activos roles en la promoción y desarrollo de la educación de párvulos. Por medio de dicha ruta, planteamos como hipótesis que la acción pedagógica de Matilde Huici estuvo caracterizada por: un marcado componente ético antropológico, el cual se basó en una clara aplicación del método científico y en un potente marco teórico, con lo cual planteó un claro, innovador y público reconocimiento a las potencialidades educativas de la formación inicial infantil.

\section{BASES INICIALES DE SUS POSTULADOS: RELEVANCIA DE LA ÉTICA, REFLEXIÓN ANTROPOLÓGICA PERSONAL, EDUCACIÓN CONTINUA Y EL RESPETO EN LOS ÁMBITOS LABORALES}

Entre 1945 y 1962 la directora de la carrera de Educación de Párvulos de la Universidad de Chile fue la española vasca Matilde Huici, tras un breve inicio de la profesora Amanda Labarca, en 1944, bajo el alero del rectorado de Juvenal Hernández. El conjunto global de las diez entrevistadas indicó de forma reiterada, consciente y clara, la importancia de la presencia de su "querida y respetada Doña Matilde", tanto como directora, docente eje de la carrera y, con posterioridad, como egresadas en sus vidas profesionales.

Como refiere un estudio sobre ella, durante sus años en España (San Martín, 2009), aquella mujer fue una destacada abogada, jueza de menores y mujeres, sicopedagoga, feminista y socialista. Provino de una familia que tuvo una buena y solvente situación económica, lo cual le permitió poder desarrollar estudios universitarios, entorno familiar que se vio marcado por la presencia de ideas laicas, distantes del catolicismo conservador de la época en España. Tuvo una activa vida pública en su país, participando en diversas acciones ciudadanas, partidarias y sociales, además de tener diversos cargos regionales y nacionales de carácter gubernamental y de viajar por Europa tomando contacto con ideas feministas y nuevos postulados educativos. En el conjunto global de su vida pública en España, promovió la igualdad de derechos entre hombres y mujeres, el carácter preferentemente laico de la educación en todos los niveles de la enseñanza, en una España y País Vasco fuertemente marcados por el clericalismo vinculado con la Iglesia Católica, además de ser una promotora activa y dinámica en ampliar los márgenes de la cobertura y dignidad de la educación en todos los ámbitos de la enseñanza. Se identificó fuertemente con la República Española, lo cual, con posterioridad al golpe de Estado de 1936 encabezado por el general Francisco Franco y a la Guerra Civil Española de tres años (1936-1939), le significó tener que tomar el triste camino del exilio de su tierra natal, a la cual nunca pudo volver ${ }^{3}$.

\footnotetext{
3 Si bien estos datos se pueden referenciar en el texto de María Nieves San Martín (2009), dichos registros también nos fueron seria y certeramente transmitidos por todas las entrevistadas para este estudio. Por ejemplo, según Alicia Navarro, ella no gustaba de contar a sus estudiantes su vida en España, ni vemos tratar de influir en sus ideas políticas, pero todas dicen saber que era feminista, abogada, socialista, psicopedagoga y periodista. Tanto Alicia Navarro como Dina Alarcón referenciaron que ella llevaba un duelo o luto por lo vivido en España, por saber que nunca podría retornar, por las personas perdidas y por la situación política creada por la dictadura de Francisco Franco. Era un duelo que llevaba el silencio y solo en espacios de mucha confianza contaba a sus colegas, ya una vez tituladas de la carrera, sin un ánimo de influir ni menos condicionar las idea de quienes la tenía como un referente educativo.
} 
Tras un breve paso por Francia, en 1940 llegó en el barco Winnipeng a Chile, como muchos españoles y españolas que fueron exiliados o no fueron capaces de vivir bajo el régimen de Francisco Franco. De esta forma vieron en Chile, gobernado en esos años por el Frente Popular de Pedro Aguirre Cerda, una opción de vida, en algunos casos con la espera de poder volver algún día a España y otras y otros con la certeza de que, si lograban echar raíces en estas tierras, estas últimas serían la base de su futura Patria. Fue en este segundo tipo de migrantes que llegó el matrimonio de Matilde Huici y Luis San Martín, quienes buscaron desarrollar su vida junto a su hijo4. Fueron acogidos en las aulas de la Universidad de Chile, donde Amanda Labarca le ayudó a trabajar en actividades de Extensión de dicha casa de estudios, ya que su título de abogada nunca fue reconocido en Chile. En dichas labores entablaron una férrea amistad, por lo que no fue extraño que Labarca pensara en ella como profesora principal de la carrera de Educación de Párvulos en 1944 y luego como directora del mismo programa.

Pero cuál fue el significado vital, modelo de vida y rol como intelectual en la educación de Doña Matilde, como cariñosamente las entrevistadas la nombran. En primer término, todas la indican como la maestra más influyente de quienes se desempeñaban en la carrera. Inicialmente, aparte del cargo de directora de Carrera, ejerció docencia en la asignatura de Psicología y Ética. Ocho de las diez entrevistadas tuvieron clases con ella en dicho ramo, evidenciando que Huici era una maestra muy exigente, tanto desde el punto de vista de los contenidos, entre los cuales dio gran valor a la reflexión personal sobre antropología, como desde el punto de vista formal; es decir, hora de llegada, presentación personal, lenguaje de expresión oral y escrito, forma de moverse tanto fuera como dentro de la sala, trato con las familias; vele decir una forma integral y global de entender tanto la educación inicial como la formación profesional de educadoras de párvulos. Para documentar lo que reseñamos, citamos un extracto referido por la educadora Luz María Roa, quien nos describió en los siguientes términos el valor y significado de la profesora Huici:

Matilde Huici... Mira yo llegué siendo una niñita que había estudiado Servicio Social, y cuando llegué me gustó la carrera. Cuando llegué al primer día, a las 8 pasada, pasada la hora, estaba la puerta cerrada y no se podía entrar hasta la otra clase. Así es que a la próxima clase todas a las 8:25 sentadas. Tenía cierto grado de autoridad ella, era muy autoritaria, pero el curso lo aceptó muy bien, porque yo llegué y dije aquí me quedo, desde la primera clase. Después quedé en la exposición: yo estudiaba $E l$ Hombre un Desconocido, del profesor este fue un premio Nobel de Medicina, Alexis Carrel, y ella nos hablaba de ese libro. Nos hacía leer, terminábamos con dolor de cabeza, había que estar atenta, atenta, pero ella logró con ese curso una afinidad total. Nosotros sentíamos esa conexión, era una cosa tremenda, era una maestra con una conexión tremenda. Yo fui formada por la Matilde, la Dina ${ }^{5}$ igual, teníamos todas una conexión tremenda. Nos dio un contexto social, histórico de la importancia de la

\footnotetext{
${ }^{4}$ Luis San Martín había tenido un primer matrimonio, del cual tuvo un hijo, quien mantuvo el mismo nombre. Doña Matilde, como nos indicaron en más de una entrevista realizada para esta investigación, lo tomó como su hijo, adoptándolo y dándole su apellido: se llamaba Luis San Martín Huici.

${ }^{5}$ Se refiere a la educadora Dina Alarcón, a quien también entrevistamos para la investigación que sustenta el presente estudio.
} 
educación de párvulos. Ella llegó de España, había trabajado con niñas en situación de vulnerabilidad, claro, con niños, claro, con señoras que tenían problemas, ella dijo ahí que no cambiaban. Por eso ella dijo voy a trabajar con niños y niñas, porque ahí se producen los cambios, y ahí eso nos metió a nosotras, ya que ese periodo era súper importante, ese niño iba a ser un ángel o un bandido. Es decir, había que manejar todas las técnicas para sacar al niño adelante [...] es muy importante porque ahí se forman todos los valores, entonces hay que trabajar muy bien, entonces la señora Matilde, digamos, ella influía mucho en las educadoras, mucho, mucho. (entrevista a Luz María Roa, 2018: 3).

Si bien la cita es un tanto extensa, nos aporta varios elementos formativos, entregados por la profesora Huici, según señalan todas las entrevistadas, los cuales, como explícitamente remarcó la profesora Roa, marcaron el desarrollo profesional de quienes se formaron con la citada educadora. En primer término, la relevancia que le dio a los temas formales en educación, ya que como vemos -y refieren otras entrevistadas- Doña Matilde era sumamente exigente con el tema de la puntualidad en el arribo a la sala de clases, ya que muchas nos indican que ella transmitía que una educadora, por la relevancia de su labor, debía estar mínimo quince minutos antes en la entidad en la que fuera a desempeñarse, para así dar a los entornos familiares una gran relevancia al desarrollo de la educación de párvulos. Este valor de los temas formales se vio expresado en niveles altos, acordes a las exigencias de una profesional universitaria de la educación de párvulos, tanto en la expresión oral, como en la escrita de estas profesionales. Además, se hacía, con el mismo ejemplo de la maestra Huici, hincapié en la pulcra, sobria y elegante presentación personal de la educadora, ya que por dicha vía se sostenía que transmitía respeto y valoración por su labor profesional, humana y sobre todo educativa.

Junto a ello, en la cita de la profesora Roa podemos ver un fuerte influjo que le dio, tanto en la asignatura de Ética como de Psicología, a la formación y sobre todo reflexión personal sobre conceptos del ser humano. En la cita se hace referencia a Alexis Carrel, autor que muchas otras educadoras señalan que Huici hizo leer a múltiples generaciones. Por medio de dichas lecturas y otros textos complementarios, buscaba que sus futuras educadoras se formaran con una rigurosa reflexión sobre ellas mismas, su rol profesional, las bases éticas y sobre todo valóricas que se buscó impregnar. En muchas entrevistas se indica que Huici señalaba a menudo "que no puede formar quien no está formada", de modo tal que el trabajo intelectual tenía como meta u objetivo principal crear la virtud de que sus estudiantes desarrollaran una profunda reflexión personal, de forma que ellas mismas, de forma libre y autónoma, con los conocimientos entregados y sus propias vivencias tanto pedagógicas como existenciales, formaran su propia y crítica visión sobre ellas mismas, en cuanto profesionales, pero sobre todo en cuanto a personas, con valores claros, permanentes y sólidos, los cuales serían la base central de su futura acción como educadoras.

Finalmente rescatamos de la cita de Luz María Roa, que todo el juicio y valoración positiva que desplegaba Huici como docente y educadora integral nació de su propia reflexión sobre su vida previa al arribo a Chile. Como se dijo antes -y en parte se infiere de la cita que comentamos- la maestra española vasca realizó una amplia labor pública, social y política en España, destacando su trabajo como abogada y jueza de mujeres, donde buscó reinsertar en la sociedad a féminas que habían ejercido la prostitución. Como sostiene Roa, 
Huici se dio cuenta de que en Chile-pese a lo necesario que era dicho trabajo en la Corte- la educación de párvulos era más central, ya que, por una parte, con la extensión y buenos resultados en la misma, se podían ahorrar y evitar muchos males y problemas sociales, como se juzgaba en la época que era la prostitución femenina. Debido a ello, Huici desarrolló una labor clave -junto con otras integrantes del equipo docente de la carrera-: convencer con el propio testimonio vital, transmitido en las clases, rigurosas, exigentes, serias y participativas, que la labor de una educadora es transcendental en la lucha contra los males sociales que vivían los niños y niñas en las aulas de los jardines y en la educación preescolar de dichos años en Chile.

Dicha conciencia de ser el primer y más vital eslabón, pese al bajo reconocimiento social que se le daba en la época en Chile, fue el legado más grande que vemos que Huici entregó en sus 18 años de docencia y gestión a cargo de la carrera. La conciencia de que la labor docente de una educadora podía -en palabras de Roa, quien cita a la maestra-formar "un ángel o un bandido", dándole así el contexto histórico-social para Chile y el mundo de la relevancia pública de su futuro desempeño laboral. Este fue el verdadero sello con que las tituladas de esta carrera salieron a su vida laboral y, como veremos, también social. Dicha mirada sobre el significado y relevancia de su profesión fue el eje de la acción y presencia de Huici en ellas. Todo lo anterior se debía a la importancia que le dio a la educación de esta primera infancia, de las y los párvulos, ya que es la edad central para formar los valores vitales de un ser humano: respeto, responsabilidad, esfuerzo y honradez.

Un segundo eje de los contenidos centrales transmitidos por Huici en su extensa labor en esta carrera universitaria, fue que la educación era un proceso permanente y constante, en el cual la educadora siempre debía estar dispuesta a aprender y a poder trabajar en equipo, siempre al servicio de sus niños y niñas. Para documentar y comentar esta temática, citaremos parte de la entrevista realizada a Ester Pretch, quien se formó en una de las primeras generaciones de educadoras de párvulos de la Universidad de Chile; quien además llegó, a fines de la década de 1970, luego de su paso por Mulchén, a ser académica de esta casa de estudios en el área de prácticas, además de ser una de las maestras fundadoras de esta carrera en la Pontificia Universidad Católica de Santiago. Junto a todo lo anterior, Pretch mantuvo un constante trabajo en jardines, en sus primeros años ligada a la Alianza Francesa; después del 11 de Septiembre de 1973 trabajó en JUNJI y con el tiempo creó el Instituto y luego Universidad Educares.

La profesora Ester Pretch inició su vida laboral en la Alianza Francesa a cargo de la educación de Kínder y Pre Kínder. En dichos primeros años de vida laboral, desarrolló una intensa y fructífera acción innovadora, que en sus palabras era "los que había aprendido en la carrera". Por lo mismo adquirió buenos resultados y reconocimiento tanto de sus pares como de las familias que tenían a sus párvulos en dicha institución educativa particular. Dentro de este contexto, citamos las palabras de Pretch sobre Huici:

Mira, ahí tuve algunos desencuentros con la madame Bourseau, pero teníamos a nuestras profesoras que siempre estaban dispuestas a ayudarnos. Manteníamos buenas relaciones con nuestras formadoras. Por ejemplo, la señora Matilde incluso vino a verme cuando tuve a mi primera hija. Era una persona muy seria, muy afectuosa pero que no quería demostrar afectos. Era muy especial de carácter ella. Le conté a 
ella lo que me estaba pasando y me dijo "Mire Ester, es muy común entre profesionales --madame Marite Bourseau tenía 52 y yo tenía 20 años [...] A todo esto, nos vimos un tiempo atrás y nos dimos un abrazo muy apretado-. Ella ve en ti a una persona que está en posibilidades de llegar mucho más allá que donde ella llegó. Son celos naturales de algunos profesionales". Con eso yo empecé a dominar la situación, también preparé a una empleada que había como auxiliar de párvulos para que me colaborara, y me aceptaron en la Alianza Francesa; ella fue una de las primeras auxiliares de párvulos (entrevista a Ester Pretch, 2018: 5).

En el registro presentado vemos cómo la profesora Matilde entendía que -si bien la formación en los años universitarios era muy relevante, como vimos más arriba- la educación debía ser un proceso continuo y permanente, que no se terminaba con la adquisición de un título universitario, que, en esos años, por la baja cobertura del sistema, daba un reconocimiento social mucho más grande que en la actualidad. La educadora debía, como fue el caso de la profesora Pretch, estar dispuesta siempre a aprender, a cambiar sus conductas, estilos y formas, en función de una mayor felicidad de sus niños y niñas. No bastaba tener la razón, la profesora Pretch tenía resultados muy positivos, había que tomar en cuenta el contexto de cada institución, como era el caso de la madre superiora, quien, como muchos jefes y jefas en el sistema educativo, estaba celosa de los buenos resultados de aquella Ester Pretch "jovencita", como nos dijo previo a la entrevista. De esta forma, con atención y respeto, la profesora Matilde le ayudó a mejorar las relaciones con las otras colegas y con la jefa, ayudándole a descubrir que, con un mejor trabajo en equipo, colaborativo y respetuoso, lograría muchos más frutos.

Ese aprendizaje lo hizo la profesora Pretch, como nos documentó en otras partes de su entrevista, con esa visita a su casa, una vez titulada, de Doña Matilde. Un diálogo profesional, simple y sencillo, entre dos educadoras que miraron juntas un problema, y que a partir del problema aprendieron, transformando la dificultad en una oportunidad. De esta forma queda como testimonio, como todas las entrevistadas confirmaron, que para esta maestra el proceso educativo era una dinámica permanente y vital, que se extendía durante toda la vida de una buena educadora. Siempre había que estar disponible a aprender de las otras colegas, jefas y familias, ya que solo de forma conjunta y participativa, pese a tener distintos roles, se podía orientar y mejorar los procesos educativos, que como veremos más adelante tenían como norte la felicidad de los niños y niñas.

La situación descrita en la cita precedente nos permite comentar una nueva arista que, sobre el concepto de educación, que calificamos integral, tenía la profesora Huici. En su visita demostró, con su estilo y personalidad, sobria, respetuosa y hasta aparentemente distante, una preocupación vital por su exalumna. Por esta vía evidenció que su labor formativa no terminaba con el logro de titular con los mejores registros a sus estudiantes. Había, dentro de los contextos posibles y con gran respeto por la libertad de las egresadas, que orientarlas y guiarlas en su relevante acción como profesionales de la educación de párvulos.

Con muchas de estas visitas y conversaciones -como nos documentan nuestras entrevistadas- en diálogos en diversas instancias, algunas más formales, otras más familiares, buscó de forma sistemática acompañar a sus alumnas, sobre todo en los primeros años de su desempeño profesional. Con esta ruta de forma vital les fue demostrando a las 
nuevas profesionales de la educación de párvulo, la relevancia de poder lograr, como fue el caso de Pretch, una armónica y cordial relación con entornos profesionales y familiares. Con los mismos siempre había que cuidar el respeto y cuidado, sobre todo en "cómo se decían las cosas". Esta actitud de respeto y buen trato era esencial para la reforzar los procesos educativos vitales de las y los párvulos, ya que para esta maestra estaba extremadamente claro la centralidad pedagógica de esta edad en el desarrollo vital del ser humano.

Por este camino de cuidar y orientar a sus tituladas, las encauzó a que ellas hicieran lo mismo con sus entornos de trabajo. Remarcó tanto en sus clases, como sobre todo fuera de ellas y una vez que sus alumnas estaban tituladas, que había que preocuparse por los adultos y jóvenes que trabajaban con ellas, profesionales, auxiliares, padres, madres y hermanos, ya que se necesitaban de todas las manos y voluntades para lograr que los avances en las aulas fueran en directo beneficio de los niños y niñas. Por este camino, entendía que la armonía y cordialidad con los entornos profesionales, sociales y culturales eran un eje central que buscó entregar a sus estudiantes. Escuchando a nuestras entrevistadas podemos decir que, en esta actitud de respeto, tolerancia y cordialidad en el trabajo de sus tituladas, Doña Matilde tuvo un gran éxito.

\section{TODAS SUS IDEAS Y PRÁCTICAS DOCENTES-DIRECTIVAS SE BASARON EN UN RIGUROSO MARCO TEÓRICO Y APLICACIÓN DEL MÉTODO CIENTÍFICO}

Las ideas expuestas hasta el momento, para algunos enfoques, podrían ser entendidas como maternalistas, en el sentido de que la maestra jugaba una especie de rol de madre pedagógica de sus hijas, cayendo de alguna forma en una suerte de maternalismo un tanto tradicional o sobre protector (Abett de La Torre, 2013). Además, como nos documentó más de alguna de nuestras entrevistas, a la profesora Matilde Huici la criticaron en su época sobre todo fuera del ámbito de la educación de párvulos- por proyectar un modelo educativo un tanto práctico, sin gran sustento teórico o de mayor peso intelectual.

Respetando la crítica que toda obra y acción educativa legítimamente pueda tener, no compartimos que sus ideas educativas fueran tradicionalistas $y$, menos aún, que no tuvieran una fuerte y sistemática reflexión teórica y sustento empírico. Diríamos que es justamente lo contrario, no solo por el carácter feminista de sus conocidos postulados en España, lo cual la alejó siempre de un enfoque tradicionalista o maternalista, sino sobre todo sobre su sistemática acción educativa, basada en un riguroso y constante análisis entre teorías pedagógicas y datos empíricos, metodología con la que analizó la educación de párvulos en Chile y en el Mundo, además de la formación y debates con que educó a sus estudiantes.

Para poder demostrar las claves o ejes centrales de su reflexión pedagógica, citamos a la educadora Dina Alarcón. Esta última, luego de titularse en 1954, se desarrolló entre los años 1955 y 1958 como directora de un jardín infantil en la población Laboratorio de Chile. Posteriormente realizó estudios de postgrado en Estados Unidos, para luego iniciar una carrera académica como ayudante de la profesora Matilde Huici en su cátedra de Ética y Psicología, carrera que la llevó a recorrer diversas categorías académicas en la Universidad 
de Chile, hasta ser docente titular. En la entrevista realizada, a partir de consultas sobre la profesora vasco-española, señaló que:

¡Uuh! en mi vida profesional es la mejor influencia que yo he tenido, yo todavía me acuerdo de ella. Hay una serie de cosas que se están descubriendo ahora que ella ya veía, tenía una visión impresionante, ella podía anticiparse a una serie de cosas; ahora no lo dudo porque ella fue alumna de Piaget, de Claparéde, ella fue juez de menores como les contaba en una oportunidad, trabajó en la rehabilitación de prostitutas, rehabilitación de delincuencia juvenil y llegó a la conclusión de que para que realmente se tuviera una real influencia educativa tenía que trabajarse con los niños pequeños, que los niños adolescentes ya estaban un poquitito pasados para que la influencia fuera tan grande para el cambio, valía más bien formar a los niños de una manera que tratar de rehabilitarlos. Ella trabajó mucho en España, como te decía era juez de menores, ella era sicóloga, también pedagoga, abogada. Entonces las educadoras empezaron a trabajar, como ya te decía antes, con gente que realmente se dedicaba a este tipo de cosas porque nos llamaban y decían: a usted ¿qué le parece el niño?, entonces uno daba todos los argumentos en relación con el niño, además de los argumentos en relación con la madre, porque se veía cómo funcionaban las salas cunas etc., que no era de lo mejor, porque las salas cunas estaban adscritas a la Ley del Trabajo, no a la ley de educación" (entrevista a Dina Alarcón, 2017: 3).

El registro presentado nos permite evidenciar algunas de las bases conceptuales y teóricas del pensamiento, planteamientos y acción pedagógica de la maestra Matilde Huici. Como registró la profesora Dina Alarcón, esta maestra estudió y fue alumna de Claparéde, con lo cual agregó a sus estudios de las ideas de John Dewey, María Montessori, Adolfo Ferriere, las hermanas Agazzi. El conjunto de autores citados, que no solo fueron referidos por la profesora Dina sino por el conglomerado de las entrevistadas para esta investigación, se enmarcó dentro de lo que la Historia de la Pedagogía ${ }^{6}$ e ideas educativas ${ }^{7}$ han identificado como Escuela Nueva, movimiento de renovación pedagógica que fue desarrollado desde fines del siglo XIX y durante la primera mitad del siglo XX. Esta tendencia reflexiva rescató la relevancia de la educación inicial o de párvulos, como una edad con intereses y necesidades propias. Sumado a ello, remarcó las potencialidades desconocidas y trascendentales que para el desarrollo del ser humano tenía la educación sistemática que debía desarrollarse en la edad de párvulos, calificando a la inteligencia de estos últimos como "mentes absorbentes", como se titula una de las obras de María Montessori, a quien la profesora Huici citaba en sus clases, como lo refirieron varias de nuestras entrevistadas.

Asimismo, la Escuela Nueva rescató y valoró, como veremos que hizo también la profesora Huici, a autores que se pueden definir como de tradición educativa paidocentrista. Dentro de estos últimos podemos nombrar a Rousseau, quien es considerado como el creador teórico de esta tendencia, realizando en su obra El Emilio o de la Educación una reflexión profunda sobre el fenómeno educativo, su relevancia social y, sobre todo, cómo la educación debía centrarse en el niño y sus necesidades. En segundo lugar, por orden cronológico

6 Sobre ideas pedagógicas se puede referir a una obra bien tradicional, que ostenta varias ediciones y reimpresiones, de Nicola Abbagnano y Andrea Visalberghi, 2007.

${ }^{7}$ Sobre el desarrollo de las ideas educativas remitimos a Palacios, 2010. 
debemos reseñar a Pestalozzi, el llamado paidocentrista popular, debido a la centralidad de su trabajo en diversas instancias formales de educación popular, donde su giro educativo, aparte de las ideas de Rousseau, se basó en su confianza en las similares posibilidades de aprender de los niños y niñas más pobres que los más ricos, cuando los primeros contaban con libros y emprendimientos pedagógicos que centraran su desarrollo en la educación popular. Como hizo también Friedrich Froebel, conocido como el principal promotor durante el siglo XIX de la educación de párvulos, quien implementó una nueva institución para este ámbito de la enseñanza, como fueron los Kindergarten o Jardines Infantiles. Todos estos autores, sus ideas y las citas a sus lecturas, eran frecuentes en las clases y consejos de la profesora Matilde, como los refieren las educadoras entrevistadas.

Debido a ello, nos parece dejar claro que la profesora Huici tuvo una clara orientación y fundamentación teórica, tanto sobre su acción directiva docente como, sobre todo, en su mirada integral acerca de la relevancia social. Luego veremos que lo mismo ocurría a nivel político, que debía sustentar a la educación profesional universitaria de la educación de párvulos. Esta percepción sobre el carácter teórico y reflexivo del pensamiento y acción de la profesora Huici, la sostiene la totalidad de las entrevistadas, quienes documentaron lo exigentes y rigurosas que eran sus clases, basadas en estudios y análisis críticos de los autores referidos arriba, incitando a sus estudiantes a pensar y reflexionar como dichos autores, que la tradición de educación de párvulos llama Los fundadores, podía iluminar, orientar y enriquecer su acción docente, siempre esta última adaptada y al servicio de los niños y sus necesidades.

Pero avancemos un paso más en demostrar el rigor activo-crítico y científico del pensamiento y acción docente de esta maestra. Para profundizar en esto, analizaremos la metodología general que usó en sus cátedras. Para ello citamos un extracto de la entrevista realizada a la educadora Luisa Revecco, quien en sus años de estudio -y una vez titulada de la Universidad de Chile- se desempeñó como directora, en algunos casos fundadora, de diversos jardines destinados a niñas y niños en situación de pobreza. Posteriormente se integró a la Universidad de Chile en su carrera de origen en el área de práctica, para finalizar una extensa y prestigiosa carrera profesional en la Universidad Central como fundadora, con otras educadoras, de la carrera de Educación Parvularia en dicha institución educativa. Al responder a una pregunta sobre el rol de la profesora Matilde y su relevancia formativa, nos indicó que:

Ella era la directora, la formadora, la exigente. En la parte ética era muy exigente, en la parte sicológica también. Nosotros teníamos que llevarle los problemas que teníamos en el jardín infantil, teníamos que llevarlos a los seminarios de sicología, entonces eras tú o tú el que ese día hacía, no la clase, sino que el que daba el motivo para hacer la clase: el problema de un niño que había sido abandonado, otro castigado, otro niño desobediente que nadie lo podía controlar [...] porque en esos casos habían muchos niños, porque son niños de población (entrevista a Luisa Revecco, 2017: 2).

La cita de la educadora Revecco nos entrega algunos elementos que además nos confirmaron las demás entrevistas, y que documentan cómo eran las clases de esta maestra, y en consecuencia la metodología desplegada por ella con sus estudiantes. En primer lugar, vemos que quienes debían protagonizar los procesos eran las mismas alumnas, quienes 
debían ser, con su participaciones, análisis, observación y debates, quienes le dieran sustento y desarrollo a la clase. La profesora Matilde desplegó, tanto en sus cursos de Ética como de Psicología, un delicado, constante, insistente y respetuoso proceso de transformación de sus alumnas para que fueran ellas, más que los contenidos, las que encabezaran los ejes vertebrantes que se debían desarrollar en sus aulas. La centralidad de las estudiantes sea infante como adolescente o adulto, fue un rasgo básico de quienes, como la profesora Matilde, se identificaron con reflexionar, transmitir y criticar las ideas de la Escuela Nueva y de Autores Paidocentristas, y vemos en la cita dicha acción reflexiva de empoderar a sus estudiantes en sus cátedras como una demostración clara del fundamento teórico de esta maestra en estos dos movimientos educativos.

En segundo lugar, la cita de la educadora Revecco nos indica el enfoque formativo de la maestra Huici. Lo vemos reflejado en que el contenido de los análisis se debía dar sobre la base de las observaciones de las estudiantes, donde lo central era conversar de forma reflexiva, crítica y creativa, sobre los desafíos y problemáticas que se traían a la sala desde realidades concretas de niños y niñas. En una primera asignatura, la profesora Matilde le encargaba a cada alumna que su tarea central era observar, durante todo el año, a una niña o niño concreto de su entorno. Sobre la base de sus registros, donde se evidenciaban sus problemáticas, desafíos y oportunidades, se realizaban las intervenciones, preguntas y debates, los cuales eran conducidos y guiados por Doña Matilde. En esto vemos el deseo de formar a sus estudiantes como profesionales intelectuales de la educación, con un claro dominio del método científico, donde los problemas o preguntas de investigación eran sugeridos, analizados y debatidos por las asistentes a las clases. En el segundo curso, cuando sus estudiantes ya estaban en contacto con experiencias de jardines concretos, se desarrollaba la misma metodología de trabajo, ahora como eje de los temas y problemáticas que ellas traían y observaban de sus experiencias prácticas, que como veremos más adelante se desenvolvieron generalmente frente a niños y niñas en situación de riesgo social.

Vemos entonces que la maestra española vasca buscó, en sus 22 años de docencia, formar en y sobre el método científico a sus estudiantes. La observación, la construcción de preguntas de investigación, la búsqueda de hipótesis de respuesta, el análisis de los datos recolectados con los casos de estudio o con cursos concretos, evidencian el carácter científico y riguroso de su metodología de enseñanza. Esta transmisión a sus alumnas no podía ser de otra forma, más que la misma maestra tuviera en su vida, no solo en su mente sino también en su acción cotidiana, internalizando el método científico como una herramienta central de su forma de entender y analizar los procesos educativos.

Todo lo anterior nos permite sostener que ella estaba plenamente formada y transmitía dicha metodología, la cual fue uno de los ejes metodológicos de la llamada Escuela Nueva en la historia de la pedagogía. Debido a esto, nos parecen infundados aquellos juicios que indican que esta docente no tenía un claro, profundo y permanente marco teórico, ya que su formación y docencia se basada en la aplicación constante del método científico, en la cual formó a las entrevistadas y a muchas profesionales de la educación de párvulos, evidenciando una clara, contundente y permanente reflexión teórica. Esta última era evidentemente contrastada con la realidad, que veían sus alumnas y en la realidad social, validando o mutando sus juicios a partir de una sólida evidencia empírica. Todo lo anterior fue 
constantemente referido y señalado con el conjunto global de quienes fueron entrevistadas para desarrollar esta investigación.

Nos parece que, para documentar más el pensamiento y reflexión teórica, basada en la rigurosa aplicación y mirada científica de la educación, nos debemos referir a uno de los instrumentos pedagógicos más valorados por esta maestra: el centro de observación. Este instrumento era una sala donde las estudiantes realizaban pequeñas prácticas con niños y niños en edad de párvulos, donde estaba una docente que ayudaba con la música -una de las cuales fue Juana Yáñez- donde se aplicaban y estudiaban las hipótesis e ideas que las estudiantes desarrollaban en sus clases y en las prácticas. Dicha herramienta educativa fue una de las luchas, siempre marcada por la falta de recursos, que la profesora Huici realizó desde su arribo a la dirección y que solo pudo concretar en 1955, prueba de las resistencias que había a la formación universitaria de educadoras de párvulos en la Universidad de Chile. Desde su instalación hasta la partida de Doña Matilde, dicho centro funcionó y fue un eje vertebrante de la formación de las estudiantes, siendo así un verdadero laboratorio científico para educar tanto a las alumnas, mejorar las herramientas y miradas de las docentes, como para iniciar investigaciones que pudieran tener un impacto en la sociedad.

Para poder profundizar en el rol y significado del centro de observación, citamos la entrevista de la profesora Adriana Otero. Ella, durante la década del cincuenta del siglo XX, estudió Sicología en la Universidad de Chile, integrándose como docente e investigadora a su mismo centro formativo. Posteriormente, y analizaremos su inicio, se sumó como docente de la carrera de párvulos de la misma casa de estudios, siempre manteniendo su filiación principal en sicología. Luego de una larga experiencia como profesora e investigadora, donde desarrolló muchas indagaciones sobre la relevancia de la educación de párvulos en la vida de niños y niñas, decidió formar su propio jardín, el cual llegó a tener cuatro centros de alto impacto en Santiago.

Citamos un párrafo de la profesora Otero, donde nos describe cómo fue su aproximación a la carrera de educación de párvulos, para ver el enfoque científico que buscó darle la maestra durante sus 22 años de desarrollo universitario en Chile. Frente a una consulta sobre sobre quién la contactó para hacer investigación en educación inicial, nos refirió que:

Fue muy especial, porque doña Matilde me había invitado ya repetidas veces a trabajar con ella, pero como no tenía antecedentes ni conocía nada de los niños tan chiquititos...Me resistí dos veces, hasta que ella por tercera vez me fue a buscar a la oficina y me dijo: "vengo en auto a buscarla para que vea a los niños". Me llevó al centro de observación que en ese momento existía en la Universidad de Chile, que era un lugar muy bueno, porque iban las alumnas a ver a los niños en su primera estadía en la universidad. Entonces podían tener una visión general de lo que hacía la educadora y cómo eran los niños chiquitos. Y ver a esos niños chiquitos ahí, a un ritmo de una música que tocaba doña Juana Yáñez, que era la que tocaba el piano maravilloso, fue enamorarme de los niños y decidí que verdaderamente era lo que me iba a gustar toda mi vida [...] y ahí le digo a doña Matilde que me voy a meter a trabajar con ella a sabiendas de que no sabía mucho de niños [...] "Era lo que estaba esperando que viera" me dijo, y lo demás "no se preocupe porque lo va a aprender, estoy segura". Y fue así, 
ya que de verdad es que me metí de lleno a estudiar sobre los niños chicos [...] Primero observaciones, aprender lo que era observar definitivamente, porque si bien en sicología tú estudias, pero otra cosa es estar con los sujetos y observarlos y saber qué les pasa, qué hacen, qué son, es distinto. Además, empecé a tener entrevistas con los padres muy seguido, cosa que también en la práctica no la tienes muchas veces en la carrera de sicología. Una cosa es que aprendas lo que es una entrevista y otra cosa es hacer la entrevista, sobre todo con los papás, ya que muchas veces es el papá de un niño que tiene problemas y quiere saber cómo lo puede ayudar, como aprendí de la Matilde (entrevista a Adriana Otero, 2018: 1-2).

Si bien la cita puede ser un tanto larga, nos pareció interesante referirla, ya que a nuestro juicio evidencia con claridad el carácter científico, con un claro, reflexivo y crítico pensamiento teórico que tuvo la profesora Matilde Huici. En primer lugar, podemos saber cómo funcionó el centro de observación, con escasez de material, como nos reseñan nuestras entrevistadas. En esta instancia de formación pedagógica se impartían clases, a veces con docentes y otras veces estudiantes, con niños de edad de párvulos, donde en todo momento eran acompañados por música, como lo reseña la cita sobre la maestra Juana Yáñez. En las mismas había una profesional -por muchos años la sicóloga Adriana Otero- observando el desarrollo de las actividades y dejando registro científico de las mismas. Junto a ello había otras estudiantes y docentes observando desde afuera, quienes, en sus clases, ya que este centro no solo era usado en la cátedra de la profesora Matilde, sino en otros cursos, comentaban, debatían y analizaban las hipótesis de trabajo expuestas en las clases.

Debemos decir con claridad que todo el proyecto del centro de observación, que fue una obra dentro de la carrera muy querida, defendida y cuidada por la profesora Matilde, se inserta la acción educativa y la práctica pedagógica de nuestra protagonista, en pleno marco de las ideas de la Escuela Nueva. Gracias a esta herramienta de trabajo se analizaron diversas hipótesis de desarrollo de niñas y niños, probando o testeando instrumentos pedagógicos, además de validar y/o descartar metodologías de enseñanza aprendizaje.

A partir de este intenso trabajo empírico se transformaban aquellas cosas y sugerencias que se analizaran como útiles, siendo además este centro una herramienta muy recomendada y usada tanto por integrantes de la Escuela Nueva como además de otra corriente pedagógica muy similar, la Escuela Progresiva ${ }^{8}$. Su sola existencia y funcionamiento fue vital en el desarrollo al interior de la carrera. Esta innovadora herramienta de trabajo pedagógico, obra vital de la labor educativa de la profesora Huici, nos vuelve a ratificar su filiación con el conjunto de ideas de la Escuela.

Además, la cita de Otero nos permite agregar otro soporte del trabajo científico de la profesora Huici. Si nos fijamos en los docentes involucrados hay: una sicóloga, una profesora de música, una abogada a las que agregamos una profesora de Literatura, Linda Volosky -

\footnotetext{
${ }^{8}$ Este último movimiento suele ser vinculado con la obra pedagógica del estadounidense John Dewey. Su obra y pensamiento, además de la Corriente Escuela Progresiva, fue muy influyente tanto en el movimiento docente chileno como en pensadores educativos como Darío Salas, Amanda Labarca, Víctor Troncoso y Ema Salas. Sobre esta temática ver Núñez, 1986, 2002b, 2012, 2016 y 2017; Caicedo, 1995aㅗ 1995b, 2005, 2008, 2012, 2014aㅡ, 2014b, 2016 y 2016b.
} 
cuyo aporte merece un artículo dedicado a ella-, el doctor Cienfuegos, médico destacado que enseñaba puericultura, dándoles claves de autocuidado y destacando la relevancia de la ciencia en la protección y desarrollo en una edad clave para el ser humano; junto con la profesora Segovia, quien entregaba elementos centrales de cómo alimentar y desarrollar la nutrición en los niños y niñas, tema relevante dados los grados de desnutrición que había en Chile en los años de estudio, y la profesora de música de apellido Acuña, quien además impartía clases en el Conservatorio.

En síntesis, vemos que el cuerpo docente de la carrera -una de las grandes fortalezas que todas las entrevistadas hacen mención sobre sus años de estudiante- era evidentemente de carácter interdisciplinario. Además, dicha composición reflejó un claro enfoque científico en el desarrollo de sus materias, donde se marcó la aplicación y apropiación del método científico, por medio de la relación, transmisión y análisis de experiencias significativas.

Además, postulamos que, en la conformación de dicho plantel de docentes de la carrera, como vemos reflejada en la cita de la sicóloga Adriana Otero, en la elección, formación y desarrollo de los mismos, tuvo un rol central la maestra Huici. Ella buscó con pinzas, como dicen más de algunas de nuestras entrevistadas, a las personas que hicieran clases en la carrera. Estas últimas debieron evidenciar tener un interés real por formar profesionales de la educación de párvulos, además de poseer el deseo de aprender sobre un tema en gran parte desconocido en Chile -como era el que se desarrolló en esta carrera, como se evidencia además en la cita de la sicóloga Otero. Junto a ello, el equipo educativo debía desarrollar su docencia y trabajo cotidiano en una rigurosa aplicación y análisis, eje formativo de esta carrera, además de los valores sociales ya comentados más arriba. Todo ello era orientado, con plena libertad de cátedra como veremos, por la profesora Huici, lo que se levanta como una prueba más de su dominio e internalización de método científico, sostenido por un serio y acabado marco teórico en su acción docente y directiva.

\section{EL ROL PÚBLICO Y SOCIAL DE LA EDUCACIÓN DE PÁRVULOS}

En este apartado de nuestro trabajo, analizaremos dos variables muy significativas de la acción docente y directiva de la profesora Huici, en sus 22 años de ejercicio en la Universidad de Chile. En primer término, y obviamente ligado a lo previamente expuesto, la vocación social que tuvo tanto su carrera como sus egresadas, donde se privilegió que tuvieran experiencias formativas con niñas vulnerables, lo cual surgió de una particular y novedosa forma de entender las potencialidades y particularidades de la infancia en sus primeros años de vida. En segundo lugar, el rol público con que buscó formar a sus estudiantes, ya que entendía que su carrera y sobre todo el tema de la educación de párvulo estaban al servicio de un cambio social en Chile, por medio de darle una gran relevancia a la educación formal y profesional de niños y niñas desde sus primeros años de vida.

Uno de los ejes de la acción de la profesora Huici fue su confianza, basada en un riguroso análisis científico y teórico, en las capacidades y potencialidades de las niñas y niños en edad de párvulos, pero sobre todo en aquellos y aquellas que vivían en situación de pobreza. Esta certeza de la relevancia de este ámbito de la enseñanza, ya que era novedoso, 
tomando en cuenta de que para muchos sectores sociales de esos años la educación formal debía comenzar en el ámbito primario, dejando la edad de párvulos solo al cuidado de la familia, donde gran parte de las tareas recaían en las madres y mujeres a cargo. Lo anterior se agudizaba en los sectores de pobreza, recordemos que Chile de aquellos lustros tenía más del $45 \%$ de personas en situación de pobreza extrema (Serrano et al, 2018), donde los entornos familiares debían usar a todos los adultos disponibles, incluso muchos jóvenes y niños, como fuerza de trabajo para poder juntar los recursos para sobrevivir. Debido a esto, muchos consideraban innecesario que niños y niñas que vivían en pobreza fueran a los jardines, ya que debían prepararse en sus casas para poder trabajar y ayudar a sus familias a "salir adelante" y no "perder el tiempo con las tías". Además, muchos niños y niñas quedaban a cargo de una sola persona, ya que el resto salía a trabajar, con lo cual la atenciones y cuidados, sobre todo en la estimulación y nutrición, se descuidaban o no se daban de forma profesional, manteniendo y perpetuando en círculo de pobreza.

De todos estos temas era muy consciente la profesora Huici. Sabía de las oposiciones que había tanto en el seno de la propia Universidad de Chile, como nos refieren nuestras entrevistadas, como sobre todo en la sociedad, a la extensión de la educación de párvulos a los más pobres. Muchos decían para qué gastar recursos en jardines cuando había otras necesidades sociales, salud, cobertura de educación primaria, alimentación entre otras, más relevantes. La profesora Huici entendía que había un entorno poco favorable en el ámbito público y académico, quienes no entendían la completa innovación social y pedagógica que implicaba su forma de entender y la prioridad que le dio a la formación universitaria de educadoras de párvulos.

Entendemos que esta forma de comprender la educación de párvulos surgió de una rigurosa, seria y contundente reflexión sobre el concepto de infancia, de la cual hemos insinuado algunas aristas en las páginas previas, pero que nos parece relevante detenernos ahora, en el entendido de que dicha concepción de la infancia no fue solo una evidente transformación pedagógica, que está claro que lo fue, sino sobre todo porque portaba una clara y consciente innovación social, dándole así un evidente perfil público y político al pensamiento y acción docente de la profesora vasco española, entendido este último como preocupación por la forma en que se organizaba la sociedad, más que la simple militancia en un partido político.

Pero ¿cómo la profesora Huici entendió, expresó y transmitió a sus estudiantes y al resto de la sociedad su concepción de infancia? Para comenzar estas ideas, volvemos a citar a la sicóloga Adriana Otero, quien se formó como especialista de educación de párvulo bajo la mirada de la educadora vasca-española. En su entrevista, nos comentó las siguiente:

Nunca se me olvida que una vez tomé a un niño delante de ella (se refiere a Matilde Huici) y le hice hacer así con las manitos para aplaudir, y ella me dijo "no, eso tiene que hacerlo solo el niño", hay cosas que te quedan ¿no?, ahí aprendí que verdaderamente hay que dejar que el niño lo haga (entrevista a Adriana Otero, 2018: 2).

Nos parece que el registro presentado, refrendado por el conjunto global de las entrevistadas para este estudio, nos refiere uno de los puntos basales de la concepción que 
sobre la infancia desarrolló y promovió en sus estudiantes, y en el conjunto global de la sociedad chilena, la profesora Huici. Cada niño y niña, sobre todo entre los años de párvulos, pero proyectable en toda su vida, debía ser el principal protagonista de sus procesos educativos. Era el infante quien debía descubrir la realidad, darse cuenta de las cosas, indagar sobre las interrogantes que la misma realidad le ponía, la cual despertaba sus propios desafíos. Este rol central de párvulo no implicaba que él mismo se pudiera equivocar, como se ve en la cita referida de la sicóloga Otero, pero era él eje de su propio proceso de desarrollo, quien podía y debía aprender acorde con sus necesidades, exigencias y opciones vitales.

Esta confianza en las potencialidades de aprender, conocer y crear de los párvulos, creemos que fue una de las principales novedades del aporte que desarrolló en sus 22 años de docencia universitaria la profesora Huici. En un país que escasamente creía o aceptaba este ámbito de la enseñanza, esta maestra -y a partir de ella con fuerza sus múltiples y destacadas discípulas, entre las cuales están muchas de las entrevistadas para este estudiodesarrolló, amplió y difundió la certeza de las potencialidades y riquezas de cada niño y niña entre 0 a 6 años.

En este eje de la propuesta formativa de la maestra Huici, como fue esta nueva e innovadora visión de la infancia, la educadora debía ser una acompañante de las búsquedas y desarrollo de las niñas y niños, como se ve claramente expresado en la corrección que le hizo a Adriana Otero, como quedó registrado en la cita. Desde esta mirada colaborativa y respetuosa sobre el accionar docente de las responsables de la formación en edad de párvulos, entendió que en el trabajo sobre la formación de las mismas debía educarse en el uso y aplicación del método científico, para que dicha herramienta pudiera ser una adecuada y atentamente aplicada por estas profesionales en su trabajo cotidiano con sus niños y niñas. Un intensa formación en el uso pedagógico en aula con sus estudiantes del método científico, como vimos además en el centro de observación, tuvo su origen y soporte en esta mirada sobre la infancia, su rol central en los procesos educativos sobre todo en la edad de párvulos, pero con una reflexión profunda acerca de la vida humana, basado en el respeto y centrado en las potencialidades de aprender y protagonizar el desarrollo de sus potencialidades y habilidades de niños y niñas, como símbolo de desarrollo de la libertad del ser humano, por ello la centralidad de la ética y antropología como vimos más arriba.

Esta mirada innovadora y creativa -compartida en Chile por otras y otros educadores, pero fuertemente desarrollada por la maestra Huici- debía ser el principal aporte público a la sociedad en su conjunto, que debía desarrollar tanto la carrera como las profesionales tituladas de la misma en sus vidas profesionales. Difundir estas ideas al resto de la sociedad, fue una tarea que implicó mucha fuerza y energía de esta abogada vasco-española en su presencia en nuestras tierras. Para ello se implicó en dos actividades que para ella fueron centrales. Una la creación y promoción de la Organización Mundial de Educación de Párvulos ${ }^{9}$ de su capítulo en Chile; y el segundo fue el Centro de Estudios Federico Froebel, para lo cual contó con la ayuda y protagonismo de la profesora Linda Volosky. En las acciones de organización, desarrollo, promoción e investigación que se dieron para dar vida a estas dos instancias, la profesora Huici expresó la relevancia pública que tenía difundir y sumar a más

\footnotetext{
${ }^{9}$ Desde ahora en adelante OMEP.
} 
personas en esta visión social de la infancia, donde niñas y niños debían ser protagonistas centrales de su desarrollo y capacidades cognitivas.

En este estudio hemos decidido sistematizar preliminarmente el rol jugado por la profesora Matilde en la OMEP Chile, dejando para otro estudio el Centro Federico Froebel, con el objetivo de evidenciar el aporte público que debían jugar tanto la carrera de Educación de Párvulos como sus tituladas, para por medio del mismo convencer y sumar en su visión transformadora y dinámica de la centralidad de la infancia parvularia en la educación. Para esto citamos a la Educadora de Párvulos de la Universidad de Chile, Alicia Navarro, quien desarrolló, luego de sus estudios universitarios tanto en Chile como en el extranjero, una extensa labor de promoción y desarrollo de este ámbito de enseñanza, en entidades públicas y privadas, para luego recalar en su alma mater y desarrollar una extensa y reconocida vida académica. En medio de la extensa y sobre todo interesante entrevista que tuvimos en gusto realizarle, la maestra Navarro nos comentó:

También tuvimos la oportunidad, en los primeros años, de conocer gente a muy interesante, muy interesante. La señora Matilde era un personaje muy importante para la sociedad chilena, tanto que cuando creó OMEP la gente que asistía a las reuniones era toda gente destacada del país. Te puedo nombrar a la doctora Bitrán, te puedo nombrar al doctor Baeza Goñi, al doctor Adriasola -director de la escuela de salubridad-, al doctor Cienfuegos -creador de la pediatría social-; te puedo nombrar a Julita Reveco, quien era la presidenta del colegio de asistentes sociales. Mira no recuerdo en este momento a la presidenta del colegio de enfermeras... y así, era gente muy interesante la que asistía y muchos de ellos eran los que daban cursos en el verano por la Universidad de Chile. Y nosotras los seguíamos, porque como educadoras estábamos ansiosas de mejorarnos, de ampliar nuestros conocimientos, en fin. (entrevista a Alicia Navarro, 2017: 2).

El registro presentado nos habla de varios matices que tuvo el rol público que la maestra Huici buscó darle tanto a la carrera de educación de párvulo como a la acción y vocación docente de sus tituladas. En primer lugar, vemos cómo en esta iniciativa estuvieron vinculados en el estudio, defensa y promoción de la noción de infancia que comentamos, un conjunto amplio, rico y valioso de especialidades de las más diversas disciplinas del conocimiento. En el registro se nombran profesionales vinculadas con el área de salud y la medicina, a eso agregamos Enfermería y Trabajo Social; ellas y ellos expusieron en el OMEP Chile diversas presentaciones y estudios sobre la importancia de la salud en la formación y educación de párvulos, como dichas profesionales podían y debían ser agentes promotores del cuidado y salubridad de sus niños y niñas en las aulas de sus jardines, y en sus entornos familiares.

Pero, además, estas presentaciones en salud impartidas por prestigiosos profesionales tenían como colofón -y esto fue fuertemente remarcado por el conjunto de las entrevistadas- la clara y fuerte conciencia y vocación social que expresó durante sus años de vida la profesora Huici. Fue ella -junto a un equipo de académicos- quien escogió los y las invitadas a exponer, quien pidió temas donde se subrayaba esta vocación social y preocupación por los graves problemas de salud -donde la desnutrición era una amenaza central para los niños y niñas de los sectores más pobres de Chile- como uno de los focos de 
análisis y de debate. Asistieron a estos encuentros, que eran de carácter semestral, profesionales de diversas áreas del conocimiento, además de salud, tales como: pedagogía, filosofía, derecho, sicología, economía e ingeniería. Junto a ello, eran invitados docentes de la carrera, quienes con alumnas y tituladas daban vida a estas reuniones, donde se compartían experiencias y eran verdaderas instancias de capacitación, donde la fuerte preocupación era el destino de la infancia.

De esta forma bien académica, seria y científica, la maestra Huici continuaba con su deseo de que las tituladas de su carrera tuvieran como sello el entender que debían estar capacitándose de forma permanente, para mejorar sus prácticas profesionales o, en palabras de la profesora Alicia Navarro: “[...] nosotras los seguíamos, porque como educadoras estábamos ansiosas de mejorarnos, de ampliar nuestros conocimientos, en fin" (entrevista a Alicia Navarro, 2017: 2). Esta búsqueda de ser profesionales que siempre debían y podían aprender más, era por la relevancia social, pública y política que a juicio de la maestra Huici debían tener las profesionales universitarias de educación de párvulos. No podían, era esto último entendido como un fracaso formativo, quedarse solo con los conocimientos entregados en los años de estudios universitarios. Debían complementar y enriquecer dichos saberes tanto con su práctica profesional como con nuevos conocimientos. Debido a ello, muchas de sus estudiantes siguieron estudios fuera de Chile; como hemos indicado, fue el caso de varias de nuestras entrevistadas, y otras que, por diversos motivos, no por falta de interés, no pudieron irse al extranjero, aprovecharon las distintas instancias que dio la carrera para seguir adquiriendo conocimiento.

De esta forma, OMEP Chile fue siempre un espacio donde las educadoras universitarias podían aprender nuevos conocimientos, profundizar en temáticas innovadoras y confrontar dichos saberes con sus propias experiencias en diversos jardines de Chile. Dicho deber por estar constantemente perfeccionándose, como reseñan todas nuestras entrevistadas, nos refiere a la vocación social y pública con que fue entendida esta carrera, ideas implementadas y promovidas con fuerza y vigor por Matilde Huici.

Pero además OMEP Chile, primera instancia latinoamericana de esta organización, fue una entidad que buscó vincular a la carrera, tituladas y a quienes entendían estas innovadoras ideas sobre la gran relevancia que debía tener la educación en esta primera edad, en un contexto global de promotores y promotoras de estas transformaciones a escala global. Todas nuestras entrevistadas refieren a que en OMEP se exponían temas que reflejaron los cambios que sobre educación de párvulos se daban a escala mundial, pues recibía un fuerte impulso desde organismos internacionales, tales como ONU y UNESCO. De esta forma, quienes asistían a las reuniones mensuales de OMEP Chile eran informados y estaban al día de los principales avances e iniciativas que este ámbito de la enseñanza buscaba desarrollar en diversas partes de la Tierra. Junto a esto, ya desde estos años, chilenas y chilenos fueron a exponer a reuniones mundiales de esta organización, donde en términos globales era muy reconocida y valorada la experiencia chilena, que era vista, a juicio de nuestras entrevistadas, como "muy adelantada para la época".

Con todo ello, en OMEP Chile se buscó encauzar y orientar a diversos actores y actrices interesados en la promoción de este ámbito de la formación universitaria y en este sector educativo, incluyendo en sus actividades a educadoras de otras ciudades, como Valparaíso y 
Concepción, las que además hacían actividades propias en sus espacios de provincias (actuales regiones). Detrás y como motor de dichos impulsos, estaba la noción social y pública que sobre infancia hemos comentado arriba, conceptos que tuvieron como eje central la acción educativa, docente y pública de la maestra Huici.

Finalmente, no podemos terminar este estudio preliminar sobre las ideas centrales de esta gran educadora, sin referirnos a una de las temáticas que marcó la vida profesional de las tituladas de esta carrera. De forma puntual analizaremos el impacto de la práctica profesional que debían realizar, junto con un seminario de grado para poder obtener sus títulos universitarios. Para presentar esta problemática, citaremos a la educadora Ivonne Fontaine, quien luego de titularse fundó la carrera de EPA en la Universidad de Concepción, la segunda en Chile, la cual encabezó hasta que trabajó en JUNJI, en la década de 1970. Posteriormente desarrolló una extensa vida académica en la Universidad de Católica de Valparaíso, para crear en la década del 2000 de carrera de EPA en la Universidad de Valparaíso. Hoy encabeza OMEP, a la cual pertenece desde los años sesenta, en su sección de la Región de Valparaíso. En medio de su entrevista, la profesora Fontaine nos señaló que:

[...] mi práctica fue en la Quinta Normal. Ahí mí me tocó hacer la práctica en un centro antialcohólicos, que yo tenía que baldear todos los lunes porque los alcohólicos, su centro antialcohólico el fin de semana, lo transformaban, ya que tomaban. Entonces yo tenía que baldear. Además, ese centro de la Quinta Normal no tenía sacos y había unas pequeñas panderetitas que llegaban hasta por ahí. Entonces el frío se colaba, era muy helado. Yo tenía a mi cargo 25 niños, pero mi compañera, que tenía los otros 25 fue solamente tres veces en todo el semestre; por lo tanto, yo tenía 50 niños y estaba esperando guagua también, así es que yo trabajé todo el semestre con 50 niños desde los 2 hasta los 6 años. Yo me acuerdo de que tenía un niñito, Pedrito, no se me ha olvidado nunca, que solamente llegaba con una camisita hasta acá, ya que no tenía nada más, en pleno invierno con un frío de morirse. Yo le tenía que llevar de repente algunas cositas para que se pusiera porque, además, pobre niño, tenía problemas estomacales, bueno obviamente tenía que haber estado desnutrido ese chiquitito, y en general los niños estaban solos conmigo (entrevista a Ivonne Fontaine: 2018: 5).

El registro presentado nos refiere varias temáticas de la relevancia que se le dio a la práctica en la carrera, tareas inspiradas en las ideas de Doña Matilde. En primer lugar, las alumnas debían desempeñarse en jardines que atendieran de forma preferente a niños y niñas en situación de extrema vulnerabilidad. Eran esos infantes pobres, el objeto y objetivo preferente de la existencia y formación de la carrera de la Universidad de Chile. Se buscaba, tarea en la cual hubo bastante éxito, que sus tituladas tuvieran como vocación preferente ir a lugares donde las carencias fueran la norma, donde con su acción y conocimiento pudieran impactar y beneficiar a dichos infantes, de modo que tuvieran una esperanza de poder salir del terrible círculo de pobreza, en un país que tenía en dichos años más del 50\% de su población en torno a los límites de extrema pobreza.

Dichas prácticas en terrenos difíciles, donde las limitantes eran pan de cada día, como refieren todas nuestras entrevistadas, donde debían ir a las practicantes e idealmente las futuras profesionales de la Casa de Bello. Había en dicha noción la idea, expresamente reseñada por la profesora Matilde según los registros recogidos para este estudio, de que se 
formaba la verdadera vocación de una educadora profesional de párvulo: en servicio y en ayuda de los más pobres de país. Para ellos y ellas se creó esta carrera, para dichos infantes la profesora Matilde hizo grandes esfuerzos con el fin de mantener con vida el programa universitario, con profesionales multidisciplinarios. Había que ir a situaciones complejas, donde las condiciones reflejaban los vacíos y carencias sociales, donde cada una descubriera el valor de lo que podía realizar delante de esos niños y niñas, donde a través de dicha experiencia pudieran perfeccionarse y reflexionar, de modo de formarse como verdaderas profesionales, con amplio sentido social, entendiendo a este último como un claro valor de servicio público y político hacia los más pobres.

Además, estas estudiantes debían enfrentar -con extrema creatividad, sin grandes críticas ni lamentos- los terribles problemas sociales que afectaban a la población infantil chilena en los años de estudio. Debido a ello convivían con la desnutrición, la falta de ropa, problemas de infraestructura o la inexistencia de agua potable, falta de espacios adecuados -vemos cómo en la cita la sala era un salón que durante los fines de semana era ocupado para beber alcohol en exceso- además de la violencia intrafamiliar. Todas esas problemáticas eran expresadas en la carrera, pero las mismas no debían ser freno para que estas estudiantes y las futuras profesionales pudieran sacar lo mejor de las potencialidades e intereses de sus niños y niñas. Había una confianza, que nacía de un claro juicio político y científico encabezado por la profesora Huici, en que los más pobres eran capaces si recibían una buena educación de párvulos, como la que entregaban sus practicantes y tituladas, capaces de aprender y desarrollarse con infantes que tuvieran en sus vidas más comodidades.

En definitiva, aquella práctica profesional terminaba como un sello en rol público, político y social para estas educadoras, al servicio de los niños y niñas, además de sus entornos familiares, los más pobres de Chile, noción que fue fuertemente enraizada, como refieren todas nuestras entrevistadas, por las ideas y principios de la querida Doña Matilde.

\section{A MODO DE CONCLUSIONES}

Al terminar este estudio preliminar sobre las ideas, prácticas e influencia educativa de la profesora Huici, nos atrevemos a plantear algunas reflexiones. En primer término, recordamos que nuestro objetivo fue analizar las propuestas educativas de la maestra vascoespañola en la formación y desarrollo de la carrera universitaria de educación de párvulo entre los años 1944 y 1964 en la Universidad de Chile. A partir de dicha meta, enarbolamos como hipótesis, a nuestro juicio validada en el análisis de las entrevistas, que la acción docente de Huici estuvo marcada por una profunda y permanente reflexión éticaantropológica personal y con sus estudiantes, la cual valoró el trabajo colaborativo y respeto profesional, basado esto en un claro marco teórico y aplicación sistemática del método científico, lo cual gestó una innovadora y profunda mirada de la relevancia social, política y educativa de la educación de párvulos.

Junto a lo anterior, indicamos propuestas para futuras investigaciones sobre el desarrollo universitario de la educación de párvulos, como del conjunto global que impulsó a la educación inicial, durante el Estado Docente con crecientes niveles de responsabilidad 
en sus aulas; es decir, entre los años 1920 y 1973, cronología explicada en el primer apartado, ambos temas fuertemente marcados por el desarrollo académico desarrollado por la profesora Huici.

En primer lugar, las 10 entrevistadas son una clara herencia de estos años de estudio. Los registros confeccionados sobre la base de las conversaciones realizadas nos permiten afirmar con certeza que dichas diez actrices de la educación inicial fueron estelares protagonistas del desarrollo innovador, constante, persistente y fuertemente resistido de la educación de párvulos durante al arco temporal inicialmente estudiado. Creemos que ellas son un registro vivo de la memoria histórica de las luchas, éxitos, dolores y alegrías con las que convivió la educación de párvulos en estos lustros. Debido a ello, debemos decir que nos parece justo que cada una de ellas debiera merecer un estudio propio sobre su acción, planteamientos, prácticas y reflexiones educativas, ya que las mismas serían fuente de inspiración no solo para los procesos de formación académicos universitarios de formación de educadoras de párvulo, sino sobre todo de reflexión sobre la identidad profesional de las actuales protagonistas del sector inicial de la educación. Estas diez maestras -no hay otra palabra que las aglutine mejor- con sus coincidencias y divergencias, desarrollaron una acción innovadora, contracorriente y muy fructífera, pese a que la mayor parte de la sociedad no comprendió o, peor aún, menospreció su labor. Por ello nos queda una deuda eterna de gratitud con ellas por darnos sus entrevistas, aprendiendo una enormidad de educación con ellas, y el deseo de poder dar a conocer sus planteamientos y propuestas sobre cómo educar para y por la felicidad de los niños y niñas de dicha edad.

Una idea que nos ronda la cabeza, tanto al entrevistarlas como al tener el gusto de difundir resultados preliminares de este trabajo en diversas instancias con educadoras, es que la historia de la educación de párvulos resulta ser una poderosa arma política en la formación de una fuerte identidad social de dichas profesionales, comprometidas con la felicidad de sus niños y niñas. El rescate de la memoria histórica no puede ser solo un hecho neutral o simplemente académico. Se trata de mirar la historia siempre desde y sobre el presente, de entender que el pasado, sobre todo de estas diez protagonistas del mismo, nos dicen muchas cosas sobre el hoy, tanto del sistema educativo global como de la educación inicial en particular. Ese debate sobre el presente, pasado, presente, es un instrumento para perfeccionar, orientar y sobre todo motivar a la formación de educadoras de párvulo plenamente comprometidas con la felicidad presente de sus infantes y los entornos familiares que los rodean, y no como una simple y muchas veces economicista proyección de futuro. Los niños y niñas de Chile merecen ser felices hoy en sus aulas, no porque dicha felicidad sea una proyección de éxito económico para los años venideros, sino porque su alegría es un derecho, y sobre todo un deber que la sociedad tiene con ellas y ellos, deber que tuvieron y nos transmitieron, con sus diferencias, las diez entrevistadas, todas las cuales indicaron que dicha tarea les fue transmitida y formada por su querida Doña Matilde.

En este sentido, no podemos dejar de mencionar, pese a que escribimos un apartado sobre este tema, lo profundamente injusto que resulta el falso prejuicio que muchos intelectuales de la época enarbolaron sobre la maestra Huici: que "ella era fundamentalmente práctica" y que había "poca teoría en sus ideas". Hemos dejado en claro el marco teórico, profundamente actualizado en la época y dinámico de la profesora vasco-española, basado en un estudio directo y por lecturas de los principales referentes de la Escuela Nueva y la 
Progresiva. Además, hemos demostrado el uso reiterado, sistemático y orgánico del método científico en sus clases, en sus reflexiones y en sus acciones directivas, todo lo cual demostró una internalización personal de dicha herramienta cognitiva. Pero estimamos que la mejor y más irrefutable prueba, la cual estamos seguros enorgullecería a la maestra Matilde, de su claro marco teórico y su fundada aplicación del método científico en todas sus acciones, son las 10 entrevistadas, herederas y símbolos de la profundidad formativa de esta educadora europea. No solo porque las diez la reseñaron claramente como su referente teórico, científico y existencial, sino porque lo demostraron con sus vidas profesionales como educadoras en los años de estudios y en los lustros posteriores. Ellas, sus memorias y acciones son la demostración de que el prejuicio en contra de Huici es absolutamente falso, carente de justicia y de verdad.

Este trabajo de rescate, estudio y difusión de la historia de la educación de párvulos, no es solo una tarea intelectual y existencialmente fascinante, sino por sobre todo un relevante deber histórico. No podemos dejar de reseñar nuestra disconformidad con aquellos postulados, basados en la defensa del actual sistema neoliberal de educación, que refiere que el Estado Docente fue una herramienta que tuvo como fin formar una nueva élite laica y que sobre todo fue una política pública que buscó la exclusión.

Es muy cierto, y ya fue demostrado con buena base empírica por Amanda Labarca (1939) y por la extensa obra del maestro Iván Núñez, que el Estado Docente no logró sumar al conjunto total de la población a sus aulas. Ello se debió, y esto se debe reafirmar con claridad, a que existieron sectores y grupos de interés que no permitieron una extensión mayor del mismo, sobre todo en el ámbito rural, y donde pudo avanzar, de forma preferente en espacios urbanos, tuvo siempre graves problemas presupuestarios, los cuales limitaron su impacto en un conjunto más amplio de infantes y jóvenes. Pero negar su existencia, pero sobre todo el deseo y lucha de quienes lo concibieron y defendieron como el principal deber social para con los sectores más pobres, reconociendo así que la educación en todos sus niveles fue una demanda permanente y de larga duración de los diversos sectores subalternos en Chile, es un postulado que la sola existencia de Matilde Huici, de su obra y de las entrevistadas -con sus ideas y vidas profesionales- y de muchas más actrices y actores del Estado Docente, desmienten con sus vidas y acciones en pro de una educación más democrática, participativa, activa y justa.

La escucha y el estudio de la historia de la educación de párvulo, como de los ámbitos primarios y secundarios, desmiente con múltiples y sólidas evidencias empíricas y teóricas, el postulado que pretende mostrar al Estado Docente como una política pública que buscó mantener la exclusión y que solo fue una memoria de una elite laica. Fueron y son porque muchos y muchos siguen vivos, como Doña Matilde, Linda Volosky, Rebeca Soltanonic, Carmen Fischer, Dina Alarcón entre otras, quienes con sus acciones en pro de una mayor participación de los sectores más vulnerables en el sistema educativo, quienes permiten afirmar que el Estado Docente fue, con sus límites y falencias, una política pública que recogió y resignificó una demanda social, sobre todo de sectores populares y grupos medios por tener el derecho, garantizado en la Constitución de 1925, de tener un sistema público gratuito y sin fines de lucro, que permitiera a grupos más amplios de la población tener en la educación una herramienta de movilidad y cambio social. Negar esto es contradecir una numerosa evidencia empírica, donde nuestras entrevistadas son un claro registro de ello, pero sobre 
todo es un intento de validar las transformaciones educativas realizadas post 1973, las cuales han tenido como un norte claro negar la memoria y valor histórico y político del Estado Docente como la principal política pública social del siglo XX en Chile.

\section{REFERENCIAS BIBLIOGRÁFICAS}

Abbegnam A. Visalberghi F. (2007). Historia de la Pedagogía. México, Fondo de Cultura Económica.

Abett de La Torre, P. (2011) Sirviendo a la Patria: Las maestras kindergarterinas en los albores del sistema de educación parvulario en Chile (1905-1915). En Anuario de Historia de la Educación Argentina, Volumen 12, Número 1, Buenos Aires. Rescatado de $\quad$ http://www.scielo.org.ar/scielo.php?script=sci arttext\&pid=S2313$\underline{92772011000100007}$

Abett de La Torre, P. (2013). Conformación y desarrollo del sistema parvulario chileno, 19051973: un camino profesional condicionado por el género. Tesis para optar al doctorado interuniversitario La Perspectiva Feminista como Teoría Crítica. Universidad Complutense de Madrid, España.

Alarcón, D. (1986). Evolución del concepto de educación parvularia en Chile desde 1906 a 1956. En Perspectiva, Número 2, Santiago.

Araya, X., Iturriaga, X. y Silva, B. (2018). Propuesta curricular de educación parvularia: desde la voz de sus protagonistas. Ediciones CECA-UDLA, Santiago.

Caiceo, J. (2005). Algunos antecedentes sobre la presencia de la Escuela Nueva en Chile durante el Siglo XX. En Anuario de Historia de la Educación Argentina, Número 6, Sociedad Argentina de Historia de la Educación, Buenos Aires.

Caiceo, J. (2008). La presencia de la Escuela Nueva en los Premios Nacionales de Educación en el siglo XX. En Revista Historia y Perspectivas, Número 38.

Caiceo, J. (2011). Desarrollo de la educación parvularia en Chile. En Revista Historia de la educación Brasileña, Volumen 14, Número 34, Río Grande del Sur, Brasil.

Caiceo, J. (2012). Pensamiento Pedagógico en Chile en el siglo 20 y sus proyecciones. En Cadernos de História da Educação, Volumen 11, Número 1, Uberlandia, Brasil.

Caiceo, J. (2014a). Hernán Vera Lamperein y su participación en el movimiento de renovación gradual de la educación secundaria en Chile. En Revista Historia de la Educación brasileña, Volumen 18, Número 42, Porto Alegre, Brasil.

Caiceo, J. (2014b). Amanda Labarca: importante educadora feminista en el siglo XX en Chile. En Cadernos de História da Educação, Volumen 14, Número 3, Uberlandia, Brasil. 
Caiceo, J. (2016a). Génesis y desarrollo de la Pedagogía de Dewey en Chile. En Revista Espacio, Tiempo y Educación, Volumen 3, Número 2, Salamanca, España http://www.espaciotiempoyeducacion.com/ojs/index.php/ete/issue/view/6

Caiceo, J. (2016b). Surgimiento de los principios de la escuela nueva en Chile y Darío Salas. En Revista Educación, Cultura e Sociedad, SINOP, Volumen 6, Número 1.

Caiceo, J. (2017). Orígenes y principales exponentes del laicismo, en su vertiente educativa, en Chile. En Revista de Historia de la Educación Online, Volumen 21, número 51, Porto Alegre, Brasil. http://www.seer.ufrgs.br/asphe/issue/view/2822/showToc

Cisterna, S. (2014). Del juego al trabajo": La Educación Preescolar en Chile, 1889 - 1914. Registros de los agentes educativos. Tesis de grado para optar a los grados académicos de Licenciado en Historia, Licenciado en Educación y Título Profesional de Profesor de Enseñanza Media en Historia y Ciencias Sociales. Universidad de Valparaíso, Chile. S/E.

Grabivker, M (2012). Los con-textos de la infancia que sustentan la formación del Educador/a de Párvulos. En Goldrine, Tatiana (editora). Contextos y desafíos para la formación inicial del Educador/a de Párvulos. Valparaíso, Chile, Ediciones Universitarias de Valparaíso, PUCV.

Grabivker, M. y Cisternas, S (2017). "Comprensiones de la infancia en los inicios de la educación preescolar". En Benjamín Silva 8compilador). Historia social de la educación. Tomo 3. Instalación, auge y crisis de la reforma alemana 1880 a 1920. Estudios finales. Santiago de Chile, Ediciones UTEM.

Hernández, R. y Zamorano, L. (2016). El pensamiento y acción social en el profesorado de regiones durante el primer Gobierno de Arturo Alessandri (1919-1925): el caso del profesorado primario de Ancud y su Boletín Escolar. En Silva, Benjamín (compilador). Historia social de la educación chilena. Tomo 2. Instalación, auge y crisis de la reforma alemana. Pensamiento, pensadores y demandas educativas. Santiago de Chile, Ediciones UTEM.

Mayorga, R. (2014). Consensos aparentes, peligros ocultos: instruir y educar en la escuela chilena 1930-1960. Ariadna histórica. Lenguajes, conceptos y lenguajes, Número 3. En http://www.ehu.eus/ojs/index.php/Ariadna/article/view/11172/pdf 9

Mayorga, R. (2018a). Una educación nueva para un nuevo individuo. En Serrano, et al (2018). Historia de la educación en Chile (1810-2010). Tomo 3 Democracia, exclusión y crisis (1930-1964). Santiago de Chile, Taurus.

Mayorga, R. (2018b). Las grandes reformas pedagógicas. En Serrano, et al (2018). Historia de la educación en Chile (1810-2010). Tomo 3 Democracia, exclusión y crisis (1930-1964). Santiago de Chile, Taurus.

Mendoza, Marcelo y Ferrer, Rosario (2015a). Los niños del '70 (el día que nació la JUNJI). Ediciones de la JUNJI, Santiago. 
Mendoza, M. y Ferrer, R. (editores) (2015b). Del buen salvaje al ciudadano (la idea de infancia en la historia). Santiago de Chile, Ediciones de la JUNJI.

Núñez, I. (1979). Tradición, reformas y alternativas educacionales en Chile, 1925-1973. Santiago de Chile, Ediciones VECTOR.

Núñez, I. (1982a). Educación popular y movimiento obrero: un estudio histórico. Santiago de Chile, PIIE.

Núñez, I. (1982b). El desarrollo de la educación chilena hasta 1973. Santiago, PIIE.

Núñez, I. (1986). Gremios del Magisterio. Setenta años de historia: 1900-1970. Santiago de Chile, PIIE.

Núñez, I. (1988). La descentralización y las reformas educacionales en Chile 1940-1987. Santiago, PIIE.

Núñez, I. (1989). Historia del trabajo docente y formación de profesores. Santiago de Chile, PIIE.

Núñez, I. (1990). Reformas educacionales e identidad de los docentes. Chile, 1960-1973. Santiago de Chile, PIIE.

Núñez, I. (1995a). "La educación chilena en el período 1945-1990. En Lozano, Claudio y Puiggrós, Adriana. Historia de la educación Iberoamericana. Buenos Aires, Argentina, Miño y Dávila.

Núñez, I. (1995b). Hacia un nuevo paradigma de reformas educativas: la experiencia chilena. En Revista Pensamiento educativo, Número 17, Pontificia Universidad Católica de Santiago, Santiago.

Núñez, I. (1997a). El ministerio de Educación en Chile (1927-1997): Una mirada analítica. En Núñez, Iván, Cox, Cristián y Soto, Freddy. 160 años de educación. Historia del Ministerio de Educación. Santiago, MINEDUC.

Núñez, I. (1997b). Historia reciente de la educación. Santiago, PIIE.

Núñez, I. (2002a). La formación de docente. Notas Históricas. En Ávalos, Beatriz. Profesores para Chile. Historia de un Proyecto. Santiago de Chile, Ministerio de Educación.

Núñez, I. (2002b). La producción de conocimiento acerca de la educación escolar chilena (1907-1957). Santiago de Chile, CPEIP.

Núñez, I. (2003). La ENU entre dos siglos. Ensayo sobre la Escuela Nacional Unificada. Santiago de Chile, LOM Ediciones.

Núñez, I. (2004). La identidad de los docentes. Una mirada histórica. Santiago de Chile, PIIE. 
Núñez, I. (2005). El profesorado, su gremio y la reforma de los noventa: pretensiones de cambio y la evolución de la cultura docente. En Cristián Cox (Editor). Políticas educacionales en el cambio de siglo: la reforma del sistema escolar chileno. Santiago de Chile, Editorial Universitaria.

Núñez, I. (2007). La Profesión Docente: Saberes e identidades en su historia. En Pensamiento Educativo. Volumen 41, Número 2. Pontificia Universidad Católica de Santiago, Santiago de Chile.

Núñez, I. (2010). Escuelas normales. Una Historia larga y sorprendente. Chile (1842-1973). En Pensamiento Educativo. Revista de investigación de educacional Latinoamericana. Pontificia Universidad Católica de Santiago, Volumen 46, Número 1, Santiago de Chile. Recuperado de http://pensamientoeducativo.uc.cl/index.php/pel/article/view/464

Núñez, I. (2012). El preceptorado como actor social. En Serrano, Sol, Ponce de León, Macarena y Rengifo, Francisca (editoras). Historia de la educación en Chile 1810-2010. Tomo II. La educación nacional (1880-1930). Santiago de Chile, Taurus.

Núñez, I. (2013). Biología y educación: los reformadores funcionalistas. Chile, 1931-1948. En Cuadernos Chilenos de Historia de la Educación, Número 1, Santiago de Chile. http://www.historiadelaeducacion.cl/index.php/CCHE/issue/view/11

Núñez, I. (2015). La educación chilena en la República: promesas de universalismo y realidades de inequidad en su historia. En Revista Perspectivas, Volumen 14, Número 3, Pontificia Universidad Católica de Valparaíso, Valparaíso, Chile https://scielo.conicyt.cl/pdf/psicop/v14n3/art02.pdf

Núñez, I. (2016). José María Muñoz Hermosilla (1856-1931) Estudio crítico de su "Memoriandum profesional. En Silva, Benjamín (compilador). Historia social de la educación chilena. Tomo 2 Instalación, auge y crisis de la reforma alemana. Pensamiento, pensadores y demandas educativas. Santiago de Chile, Ediciones UTEM.

Núñez, I. (2017). El movimiento de los preceptores primarios (1923-1928): maximalismo, realismo y ¿derrota?. En Silva, Benjamín (compilador). Historia social de la educación chilena. Tomo 3 Instalación, auge y crisis de la reforma alemana. Notas finales. Santiago de Chile, Ediciones UTEM.

Núñez, I. (2018). "Profesores y Estado: formación docente, condición funcionaria y consolidación del gremio como actor político (1930-1964)". En Serrano, Sol et alt. Historia de la educación en Chile (1810-2010). Tomo 3 Democracia, exclusión y crisis (1930-1964). Santiago de Chile, Taurus.

Núñez, I. y Pérez, C. (2015). "Gabriela Mistral”. Educadores Latinoamericanos. Publicación UNIPE (en línea) http://educadoreslatinoamericanos.unipe.edu.ar/gabrielamistral//

Palacios, J. (2010). La Cuestión escolar. Buenos Aires, Argentina, COLIHUE.

Peralta, M. (2001). Una pedagogía de las oportunidades. Nuevas ventanas para los párvulos latinoamericanos del S. XXI. Santiago de Chile, Editorial Andrés Bello. 
Peralta, M. (2006). Cien años de educación parvularia en el sistema público: El primer Kindergarten fiscal 1906-2006. Santiago de Chile, Universidad Central.

Peralta, M. (2007). El Centenario de la primera Casa dei Bambini (1907-2007). Investigación histórica sobre: la visita de la Dra. Montessori a Argentina en 1926, el primer Jardín Infantil Montessori y la primera formación de jardineras montessorianas en Chile (1926). Santiago de Chile, Universidad Central.

Peralta, M. (2008a) En el centenario de L'Ecole Decroly (1907-2007). La pedagogía decroliana en Latinoamérica y la visita del Dr. Decroly a Colombia (1925). Santiago de Chile, Universidad Central, Facultad de Ciencias de la Educación-IIDEI.

Peralta, M. (2008b). La calidad como un derecho de los niños a una educación oportuna y pertinente. En Espacio para la Infancia, Número 28, pp. 3-14.

Peralta, M. (2008c). El derecho de los más pequeños a una pedagogía de las oportunidades en el siglo XXI. En Revista Iberoamericana de Educación, Número 47, 33-47.

Peralta, M. (2009). Los primeros jardines infantiles en América Latina. Los casos de Argentina, Nicaragua y Chile en el siglo XIX. Santiago de Chile, Universidad Central, Facultad de Ciencias de la Educación-IIDIE.

Peralta, M. (2010). El saber y hacer pedagógico en educación parvularia. Un análisis desde el bicentenario. Santiago de Chile, Universidad Central. Facultad de Ciencias de la Educación-IIDEI.

Peralta, M. (2011). Los Primeros Centros Educativos para párvulos en Latinoamérica. Segunda Parte: Los casos de Chile y Bolivia en el siglo XIX. Santiago de Chile, LOM Ediciones.

Peralta, M. (2012a). Un análisis del desarrollo curricular de la educación parvularia chilena. ¿Cuánto hemos avanzado? En Revista Docencia, Número 48, Santiago de Chile.

Peralta, M. (2012b). El pensar y sentir de Gabriela Mistral sobre la educación de la primera infancia, sus educadores e instituciones. Santiago de Chile, Universidad Central.

Peralta, M. (2013). Desde "expósitos" a personas-sujetos de sus aprendizajes: el lento transitar de los bebés latinoamericanos al derecho de una educación oportuna y pertinente desde el nacimiento. Santiago de Chile, Universidad Central.

Peralta, M. (2015). Ciento cincuenta años del inicio de la Educación Parvularia en Chile. En Revista Enfoques Educacionales, Volumen 12, Número 1, Santiago de Chile.

Peralta, M. (2018). “La reforma de 1927 y sus implicaciones en la educación parvularia”. En Silva, Benjamín (compilador). Historia social de la educación chilena. Tomo 4. Estado docente con crecientes niveles de responsabilidad en sus aulas 1920 a 1973. Agentes Escolares. Santiago de Chile, Ediciones UTEM. 
Reyes, L. (2003). Crisis, pacto social y soberanía: el proyecto educacional de maestros trabajadores. Chile, 1920-1925. En Revista Cuadernos de Historia, Número 13, Santiago de Chile.

Reyes, L. (2005). Movimiento de educadores y construcción de política educacional en Chile (1921-1932 y 1977-1994). Tesis para optar al grado de Doctorado en Historia, Universidad de Chile, Santiago.

Reyes, L. (2013). La Escuela en nuestras manos. Santiago de Chile, Editorial Quimantú.

Rojas, J. (2010). Historia de la infancia en Chile republicano 1810-2010. JUNJI, Santiago de Chile.

San Martín, M. (2009). Matilde Huici Navaz. La Tercera mujer. Madrid, España, NARCEA SA Ediciones.

Serrano, S et al (2018). Historia de la educación en Chile (1810-2010). Tomo 3 Democracia, exclusión y crisis (1930-1964). Santiago de Chile, Taurus.

Vial, G. (2001). Historia de Chile. (1891-1973). Volumen I, Tomo I. Santiago de Chile, Editorial Zig- Zag.

Vial, G. (2010). Chile: cinco siglos de Historia. Desde los primeros pobladores hasta 2006. Tomo II. Santiago de Chile, Zig-Zag.

Viviani, M. (2017). "Mujeres que cambiaron la historia de la educación parvularia en Chile”. Sitio web "Soy Educadora", revisado el miércoles 19 de septiembre 2018 https://soyeducadora.com/2017/05/15/mujeres-que-cambiaron-la-historia-de-laeducacion-parvularia-en-chile-matilde-huici/

Zemelman, M. y Jara, I. (2006). Seis episodios de la educación chilena, 1920 a 1965. Santiago de Chile, Ediciones Facultad de Filosofía y Humanidades Universidad de Chile. 